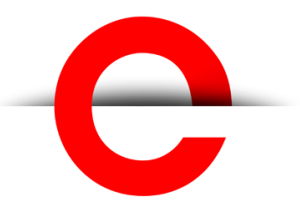

U T S

e PRES S
International Project

Management

Association Research

Conference 2017

2-4 November 2017
(C) 2018 by the author(s). This is an Open Access article distributed under the terms of the Creative Commons Attribution 4.0 International (CC BY 4.0) License (https:// creativecommons.org/licenses/ by/4.0/l, allowing third parties to copy and redistribute the material in any medium or format and to remix, transform, and build upon the material for any purpose, even commercially, provided the original work is properly cited and states its license.

Citation: Kim, S. 2018. A Philosophical Approach to Project Management (2): Project Success from an AllEmbracing Perspective based on the Project Phenomenon Theory. International Project Management Association Research Conference 2017, UTS ePRESS, Sydney: NSW, pp. 1-12. https:// doi.org/10.5130/pmrp. ipmarc2017.5685

Published by UTS ePRESS http://pmrp.epress.lib.uts. edu.au
CONFERENCE PAPER

\section{A Philosophical Approach to Project Management (2): Project Success from an All- Embracing Perspective based on the Project Phenomenon Theory}

\section{Soohong Kim}

Incheon Bridge Company Ltd., 3 Incheondaegyo Expressway, Jung-gu, Incheon, Republic of Korea (22378)

*Corresponding author: Soohong Kim. soohong.kimdincheonbridge.com

Name: International Project Management Association Research Conference 2017

Location: Incheon, Republic of Korea

Dates: $2^{\text {nd }}$ to $4^{\text {th }}$ November 2017

Host Organisation: IPMA-Korea

DOI: https://doi.org/10.5130/pmrp.ipmarc2017.5685

Published: 08/06/2018

\section{Abstract}

Throughout several million years of history, human beings have achieved being actualization through creative intervention in reality by means of consciousness activities and consciousnessbased physical activities (Lacko et al. 2014). The world has continuously developed and evolved from human's being actualization through epistemic and physical activities, creating new values (Abbasi \& Al-Mharmah 2000).

This paper identifies successful episteme as the origin of project success from the perspective that the vocation of mankind is being actualization, which is project actualization in history. It completes the conditions for project success from an all-embracing perspective by identifying the intrinsic characteristics of the truthful episteme oriented towards the absolute knowing, applying them to the project and overcoming the limitations caused by emotional convictions of the project managers' own episteme, which is differentiated from the truthful episteme. This paper confirms that the development of project identification, project action and management 
plan is the successful episteme for achieving successful results and processes by proposing Project Identification and Categorizing Structure (PICS) and Project Logic of Division and Convergence (PLDC).

The value-based results of all fields that appear in the project phenomenon, such as science, technology, politics, economy, society, culture, education, and so on, and its meaning of success are realized within the possible extent of the episteme. Therefore, this approach emphasizes the importance of the exploration of episteme that could realize the meaning of project success, and hence realizing project success in the fourth industrial age that will lead human relationships based on complex social relations and new lifestyles.

\section{Keywords}

Project phenomenon; Project success; Successful episteme; Episteme; Consciousness; Selfconsciousness, Being actualization, Project actualization; All-embracing perspective

\section{Introduction}

Mankind has made ceaseless efforts to survive and thrive under the law of nature, and created this world through being actualization while growing its population to seven billion. In order to achieve being actualization (Figure 1), which is mankind's vocation, human beings have actualized projects through a process by which spirit and body intervene in reality, pursuing civic value (Stroud, 1986; Lacko et al. 2014). In this sense, mankind's development is project development, and the pursuit of civic value is the aim of project success.

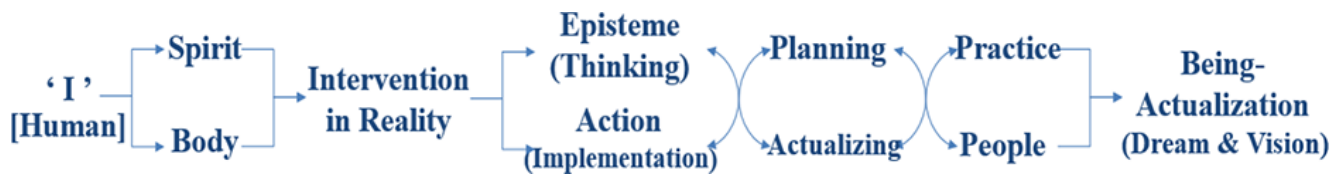

Figure 1 Phenomenon of human being actualization

Human beings' desire and need for project success, the vocation of mankind, has broadened the perspective of project success from results oriented success to the process of the phenomenon and its origin. To succeed in projects that have been enlarged, convoluted, and diversified with changes triggered by the industrial revolution and technological advancement, project management (PM) has expanded from independent and individual project management to program and portfolio management, which allows the management of convergent and complex projects. A variety of PM methods, skills, and tools have been subdivided, specialized and developed accordingly. Throughout this process, there have been diverse perspectives on project success, and there has also been the need for a comprehensive and all-embracing exploration of knowledge on project success (Shenhar et al. 1997;

Meskendahl 2010; Jugdev \& Muller 2005; Valverde, 2015).

Project success is the successful execution (project's actualization process), and its result supersedes successful planning. Successful episteme on the concept of project is a precondition for successful planning (Dvir et al. 2003). Therefore, in order to achieve project success, the identification of successful episteme is necessary and inevitable.

Hegel stated in the Phenomenology of Spirit that consciousness activities, based on the dialectical logic principle of consciousness and self-consciousness, complete the absolute 
spirit by reaching absolute knowing, in which the reality of spirit corresponds with the one of nature within the spirit itself through the concept of logic. This paper approaches the matter of project success from an epistemic perspective, differentiates the form, means and mechanism of the truthful episteme oriented towards absolute knowing, and investigates each of the intrinsic contents of the form, means and mechanism to apply them to project phenomenon. Through application, project managers can overcome the limitations of their episteme caused by emotional delusion, which appears as sensory conviction, conviction derived from the abstraction of concepts, and erroneous conviction of their physical activities. The design aimed at project actualization unfolds from project identification, establishment of project action and management plan, sublating towards the project success of all-embracing perspective.

\section{Literature Review}

The history of industrial development contributed to the creation of the present physical world, is the history of project actualization in the phenomenal perspective and has grown, derived, and expanded in the direction of pursuing the civic value. As humanity marks the fourth industrial revolution, where information participation and exchange of the community is expanding, mankind is experiencing the evolution towards a generation that requires creativity for convergent and complex designs, such as the smart cities.

Although in the past 60 years or so, the history of project management development within the history of the industrial development had centred around international organizations like IPMA, PMI, APM, etc., and developed into structures, such as the ISO, PMBOK ${ }^{\circledR}$, PRINCE $2^{\circledR}$, IPMA ICB (Individual Competence Baseline), etc., there is a lack of consensus on a consistent interpretation and clear definition regarding project success (Ika 2009; Stretton \& Crawford 2014; Milind \& Gopinath, 2016). Disputes on the extent of project success have expanded from results oriented success perspective, to the perspective of successful process and to episteme as its origin (Radujkovic \& Sjekavica 2017). Just as the 'perspective' of the Eye of Competence from IPMA ICB 4.0 (IPMA 2016) is put forward as a case that emphasizes project managers' epistemic aspects, the importance of the project managers' episteme has been accentuated and expanding (Shaw 2010). From the perspective that human's episteme is the origin of industrial development, which is a result of various project actualization, and the development of PM's body of knowledge, PM as an instinctive managerial consciousness for bringing projects to success has an apodictic relationship with projects, as the vocation of mankind.

The philosophical effort of pursuing the truth of episteme made great progress in German idealism. Kant's critical philosophy (1781/1998), which distinguishes consciousness and object and dualizes spirit and material, and identity philosophy of Schelling (1797/1979) and Fichte(1800/1987), which suggests that everything in nature is one within the spirit, was compiled by Hegel's dialectical logic philosophy, unifying duality with the dialectical logic of consciousness and self-consciousness. By the dialectical logic development of consciousness and self-consciousness, the being corresponds with the concept and the truth corresponds with conviction in the absolute knowing driven towards the absolute spirit, according to Hegel's Phenomenology of Spirit. As the absolute spirit and its episteme and logic are the truth, this paper seeks to identify the characteristics from the intrinsic elements of truthful episteme and apply them to project actualization, aiming towards the absolute knowledge (Kant 1781/1998; Schelling 1797/1979; Hegel 1807/1977). 
The exploration of the truth on the phenomenal episteme has been providing an important academic basis for PM, and the improvement in quality of episteme to achieve project success brought realistic management methodologies, such as Critical Success Factor (CSF), Key Performance Indicator (KPI), and so on (IPMA 2016). The rise of the importance of epistemic administration and management in PM, a practical field, is an instinctive and apodictic result, displaying the potential of integrating all disciplines. From such a perspective, by defining the project phenomenon's intrinsic characteristics, I previously presented that PM's area expands by growth, derivation, and expansion beyond the areas of science, technology, politics, economy, society, culture, and to nature within the sustainability of history (Kim 2015; PMIAA 2015).

This paper identifies the intrinsic elements of the episteme, as the epistemic form, means, and mechanism, and presents PICS and PLDC that resolves the confusion in episteme from the complexity caused by the two opposing logic between project identification and action which appear in the consciousness activities of project phenomenon, proving that projects could be oriented towards project success from an all-embracing perspective.

\section{Methodology}

The conceptual episteme of phenomenon is the origin of all being actualizations as the representation of the intrinsic contents inherent in episteme. In human history, the creation of the world through being actualization is the history of projects, as well as the vocation of mankind and the reaching point of our instinctive activities. The purpose of this paper is to differentiate the truthful episteme oriented towards the absolute knowing as the form, means, and mechanism to identify its inherent characteristics and propose the conditions for project success from an all-embracing perspective that subdues the limitations of the project executors' episteme caused by the delusion of the emotional conviction.

\subsection{FORM OF PHENOMENAL EPISTEME}

The form of the episteme is a fundamental condition for all phenomenal episteme and refers to, in a conventional sense, time, space and category (Kant 1781/1998; Hegel 1807/1977; Hessen 1964). Phenomenal episteme is conceptual episteme and since a project is a phenomenon, it is recognized as a concept. A concept is the content that results from the temporal-spatial categorization of feelings and emotions where the meaning and significance are given. All concepts obtain sameness from the associated structure of the characteristics based on the temporal-spatial categorical form (Kant 1781/1998; Hegel 1807/1977; Kim 2015).

As in Whitehead's (1927/1979) proposition that "The past has an objective existence in the present which lies in the future beyond itself" and in Fichte's (1800/1987) notion of the repetition of precedents and Heidegger's (1927/2008) notion of projection from the past to the future, the temporality inherent in all concepts manifests itself in history as sustainability through the dialectical principle of logic. Just as Hegel (1807/1977) presented a conceptual space that logically encompasses all of nature, and as Schelling (1797/1979) said in one of his famous quotes, "Nature is visible Spirit; Spirit is invisible Nature," all spatiality is comprehensively relational within nature. As temporal-spatial characteristics mutually inherent in concepts, all time and space manifest themselves merged in a single phenomenon in history and nature. 
Project goals and objectives, from the perspective of realization, are spatial contents where time remains still, and it is an abstract potentiality. The concept of a project, for the realization of goals and objectives to fulfil dreams and visions, attains actuality when both temporal procedures and spatial contents from the beginning to the accomplishment of a project become specified. The concepts and their elements that become specified in the procedures and contents of the project phenomenon possess sameness in their intrinsic contents, and lie in mutually-associated temporal and spatial relations. In this perspective, the area of PM expands beyond science, technology, politics, economics, society, culture, and to nature.

\subsection{MEANS OF PHENOMENAL EPISTEME}

The consciousness activities, in the means of phenomenal episteme, based on the development of concept's dialectical logic, unfold into emotional thinking reliant on feelings and emotions, intellectual thinking that captures the meaning and significance of contents as a concept, and logic-oriented rational thinking that identifies logical relations among the concepts, sublating towards the absolute spirit.

Concept is the content that the meaning and significance are given to temporal-spatial categorization of feelings and emotions. One concept divides into many and essentially becomes concrete as intrinsic contents. These concepts integrate into a single concept through the dialectical principle of logic. Hegel elaborates the dialectical activities of consciousness and self-consciousness through the three "moments" of the concept: universality, particularity, and individuality. Thus, this is plainly expressed in the proposition "The one becomes many; and the many becomes one" (Whitehead, 1927/1979; Hegel, 1807/1977). From a subjective perspective, a concept connotes many concepts within itself, and the concept becomes transformed into an objective perspective through the relations with other outside concepts; the subjective and objective perspectives on the concept manifest themselves as sameness through the dialectical principle of logic of the absolute spirit.

As such, in project phenomenon, many projects exist within one project, which itself exists as an object in relation to a variety of other external projects. The project goals and objectives develop from abstract to universal and the conceptual elements and items related to the realization of the goals and objectives are driven from diversity to unity through the dialectical principle of logic, and the logical interrelations among the concepts that form a project develop from contingency into necessity.

\subsection{MECHANISM OF PHENOMENAL EPISTEME}

I suggest in this section the mechanism of phenomenal episteme, and define the intrinsic contents of being actualization based on the temporal-spatial characteristics and properties of the concept of being, which were identified from the form and the means of episteme.

In the process by which the form and the means of episteme function, the conceptual information attained from actuality experience and ideation experience goes through the process of appropriation of data according to logical principles, which enhances the quality of information by having its data of experiences matrixed by logical order, sort, and arrangement. This improves the future design capability of being actualization (Figure 2). The project that aims at being actualization manifests itself as sustainability in history as time and relationality in nature as space. Such consciousness activities reconcile project design with actuality and affirm project success from an all-embracing perspective. This can be explained as an example, such as predictive analysis through big data, weather forecasts from a meteorological 
U T S

e PRES S

administration, and future forecasts by means of the self-learning of AI (Artificial Intelligence) (Makridakis 2017; Mayo \& Leung 2018).

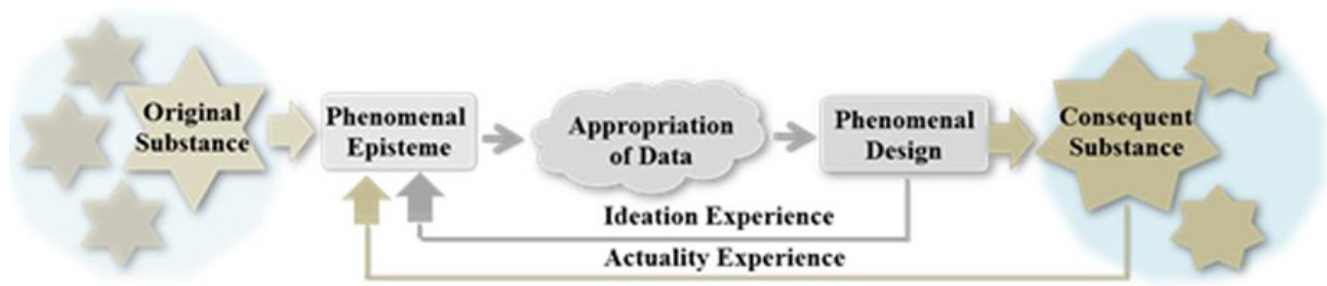

Episteme continues to memorize and informationize ideation experience and actuality experience, enhancing design capability through the accumulated information and its quality improvement.

Figure 2 Epistemic mechanism of phenomenon (EMP) (Kim 2015)

Based on the intrinsic contents inherent in episteme, that are defined from the mechanism of phenomenal episteme through its form and means, the conditions for project success from an all-embracing perspective are suggested as follows.

First, as temporal-spatial categories is inherent in the form of project, the project goals and objectives must be dualized and studied as temporal procedures and spatial contents. Second, based on the logical characteristics by which one project connotes many projects and many projects are subsumed as one project, the concept of project goals and objectives must become concrete as a detailed set of objectives and their contents, while the intrinsic contents of project must be defined within the unified associated structure of temporal-spatial categories. Third, the project goals and objectives must comply with the logical principles of procedural sustainability of time and the relationality of contents in space (Robertson \& Williams 2006).

\begin{tabular}{c|c|c|c}
\hline Phenomenal Episteme & Form & Means & Mechanism \\
\hline $\begin{array}{c}\text { Inherent Essence of } \\
\text { Episteme }\end{array}$ & $\begin{array}{c}\text { Temporal-Spatial } \\
\text { Categorization }\end{array}$ & $\begin{array}{c}\text { Essence and } \\
\text { Property }\end{array}$ & $\begin{array}{c}\text { Sustainability, } \\
\text { Relationality }\end{array}$ \\
\hline
\end{tabular}

Figure 3 Inherent essence of form, means, and mechanism of episteme

By unfolding from project identification and implementation of project action and management plan that comply with the aforementioned three conditions, project executors overcome the delusion of sensory conviction, delusion derived from the abstraction of concepts (Hegel 1807/1977; Hessen 1964), and delusion from erroneous conviction of physical activities, which are the limitations of emotional delusion that is inherent in their episteme itself, affirming success from an all-embracing perspective.

\section{Project Phenomenon}

The consciousness of project managers in regards to being actualization of dreams and visions, gains potentiality from project identification that meet the conditions for project success from an all-embracing perspective, which is drawn from the episteme that is the truth, finds conviction of actuality through the project's action plan, and gains certainty from the management plan of the project executors, through which the conviction of project success from an all-embracing perspective is self-realized (Kim, 2015) (see Figure 4). 


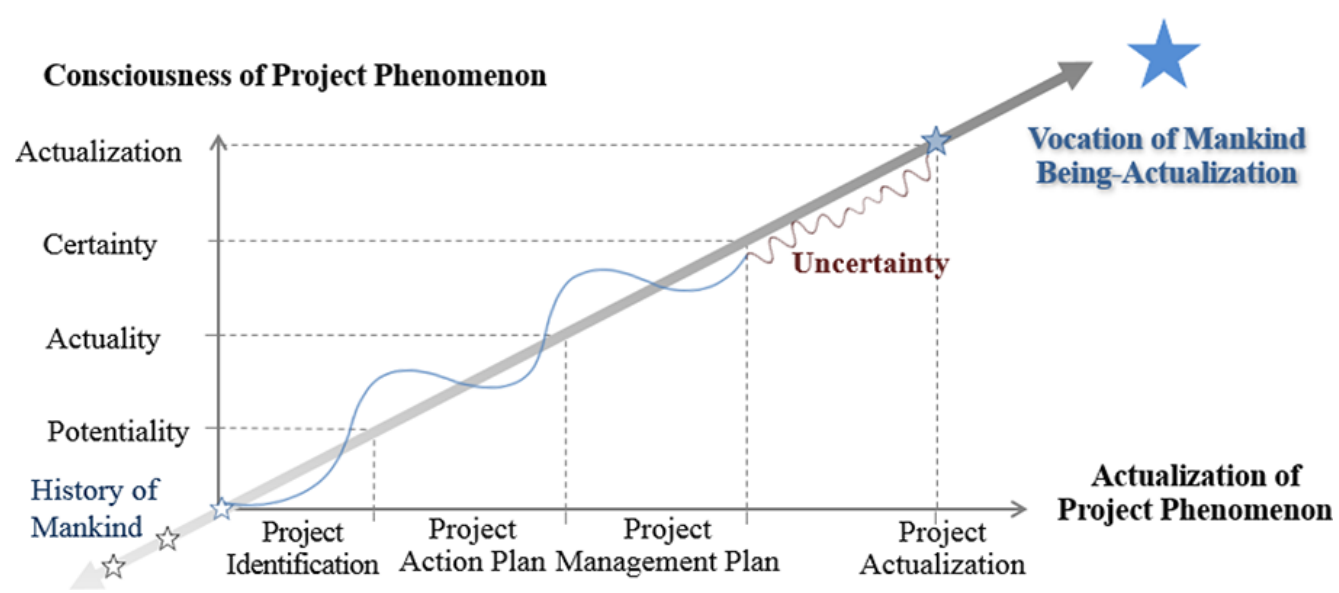

Figure 4 Development of project episteme and phenomenon

\subsection{PROJECT IDENTIFICATION}

Project identification is the identification of the universal meaning and significance of the concept of project and its intrinsic contents. It is figuring out, based upon analyses like the SWOT analysis, project environment, and stakeholder analysis, the intrinsic contents of temporal procedures and spatial contents from the beginning to the accomplishment for project goals and objectives that meet the expectations of stakeholders (Pinto \& Slevin 1988; Cox 2016). This develops in the following phases: (1) determine strategic objectives, (2) differentiate procedures and contents from the beginning to the accomplishment of project objectives, (3) identify procedural objectives and define the associated elemental objectives as well as item objectives within the elements, and (4) all projects, objectives, elements, and items are concepts, and as such, they possess sustainability within history and logical relationality in pursuing the civic values as a goal.

Many projects exist within a single project, which also may serve as an element that constitutes a larger project (Kim 2015). In the dimension of the fourth industrial revolution, where projects are becoming increasingly complicated and larger in scope, like smart cities, there is a gradual increase in the need for new and improved management tools and knowledge. Moreover, projects continually change, and the management of such changes and risks has been emphasized as a crucial element for project success of an all-embracing perspective. From this sense, I propose PICS for the design of project phenomenon.

In project identification, the intrinsic contents of temporal-spatial procedures and contents develop as (1) objective projects within the project, (2) objective elements within the objective projects, and (3) objective items within the objective elements. In Figure 5, a project such as a national agenda is categorized and subdivided into the projects of departments, divisions, and organizations on temporal procedures, of which intrinsic contents develop as elements and items. PICS provides important standards for the decision of project, program, or portfolio management, and predicts CSF from identifying the changing goals, elements, and items of each procedures and its phases of the project, designing KPI that manage such changes. Therefore, PICS, as the management of the project's temporal-spatial identification of the truth and its actualization, has an apodictic development of project success from an allembracing perspective. 


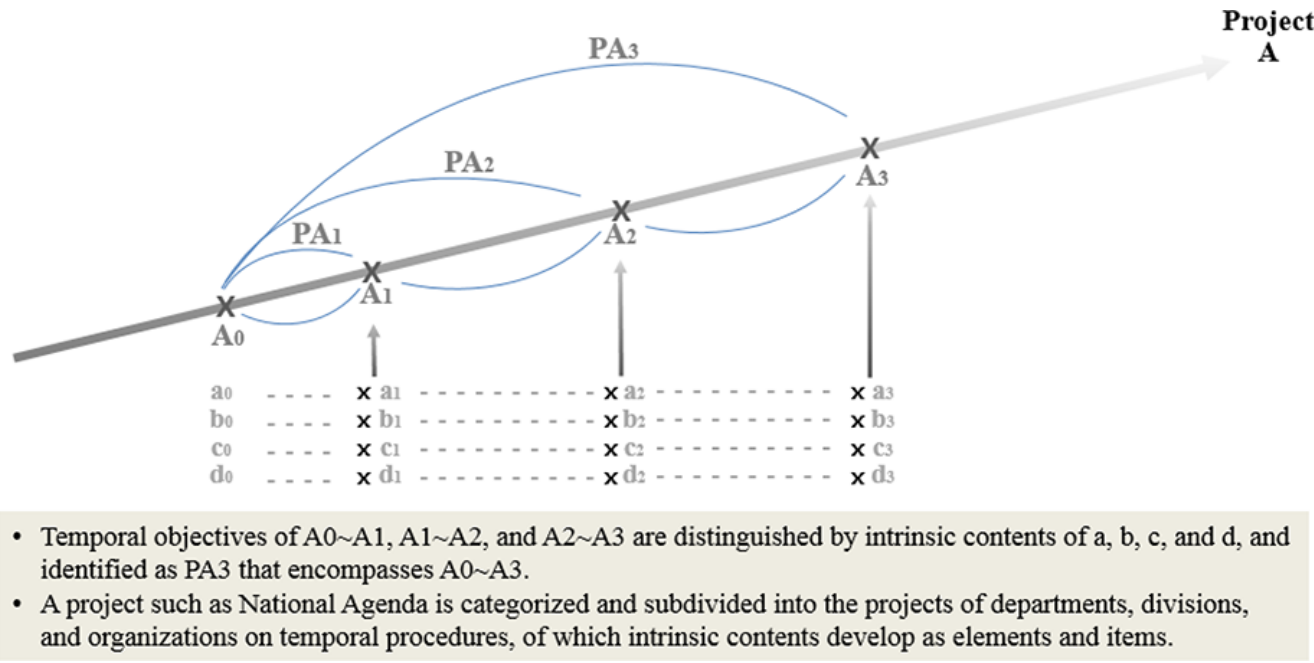

Figure 5 Project identifying and categorizing structure (PICS)

\subsection{PROJECT ACTION PLAN}

The actuality perceived through project identification is driven towards potentiality from the perspective of project actualization, and becomes fulfilled through the establishment of the project action plan. In the phase where the project action plan is established, the optimal means and methods to realize CSF, which is a set of core elements and items numerically subdivided through PICS, are determined, and tasks and KPI are assigned to project executors and executing organizations. The project executors and executing organizations then manage CSF and KPI as core elements and performance indicators needed for successful implementation of the project's strategic objectives. At the same time, project managers manage the outcomes related to procedures and contents of the project's strategic objectives, as well as examine and manage CSF and KPI associated with such processes.

As shown in Figure 6, in the development of consciousness from 'Potentiality A' to 'Actuality B' for being actualization, the objectives in project identification are broken down into their elements, and item objectives through temporal-spatial categorization and logical subdivision of procedures and contents. The elements and item objectives, which became concrete during the phase of project action, reach convergence (Whitehead 1927/1979; Green 2003) during the process of their realization and achieve being actualization as actual deliverables that belong to the actualized intrinsic contents. I suggest PLDC, a development of opposing logic between project identification and action which appear in the consciousness activities of project phenomenon. It is the development of logical consciousness merged through the actualization process from 'Potentiality A' to 'Actuality B', distinguishing the development from 'potentiality a' to 'actuality b' in the phase of project identification and the one in the phase of project action. As there are opposing thoughts that exist as division and convergence in the project actualization process, we find it difficult and complicated if this process is viewed as one. However, PLDC resolves the problems of the confusion of episteme and the complexity of project actualization process through the conceptual dualization of the information's division and convergence, defining and combining again. 
U T S

e PRES S

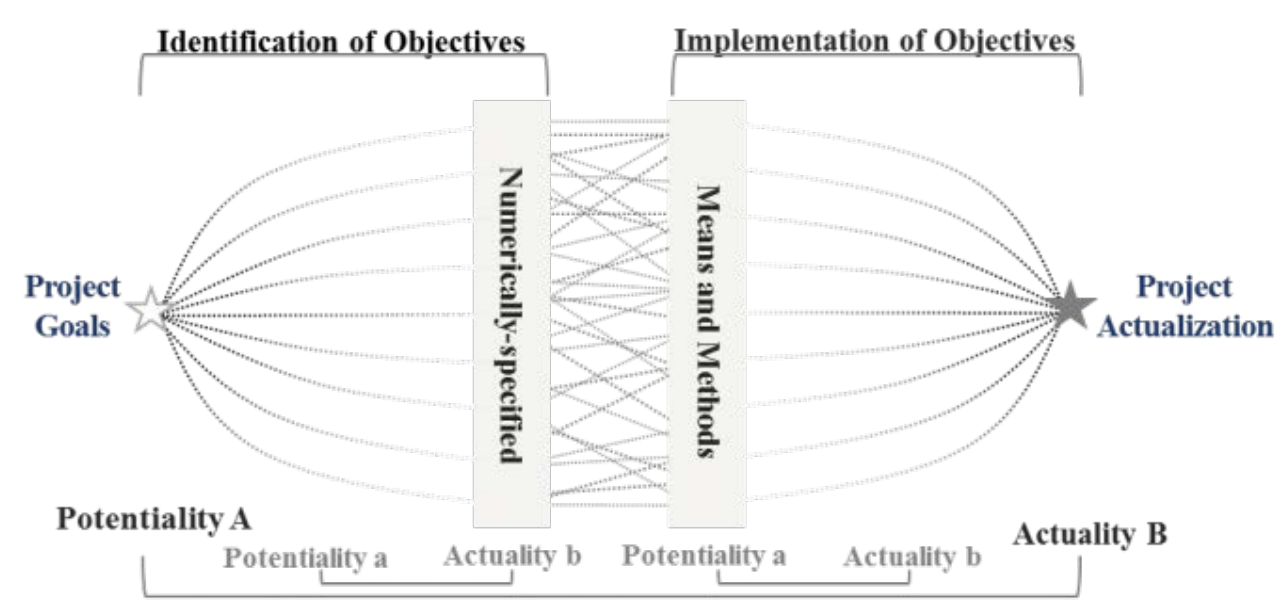

Figure 6 Project logic of division and convergence (PLDC)

\subsection{PROJECT MANAGEMENT PLAN}

The project management plan manages the implementation of the action plan to meet the conditions for project success from an all-embracing perspective. Under the project management plan, project managers utilize CSF and KPI drawn from PICS as core elements and management indicators, to examine and manage the implementation of the action plan in terms of factors such as time, cost, quality, safety, health, risk, and change. PICS systemizes the project management plan for project identification and actualization through the logical development of temporal-spatial procedures and contents related to the project's strategic objectives as well as elemental objectives and item objectives to meet the expectations of stakeholders, thereby leading to obtaining certainty of project success from an all-embracing perspective (Figure 7).

Humans, through the development of project identification, project action and management plan that meets the conditions for project success from an all-embracing perspective, overcome the sensory conviction, conviction derived from the abstraction of concepts, and erroneous conviction of their physical activities, which exists within the project executors' episteme itself, achieving project success in the outcome, process, the cause, and pursue civic values within the

\begin{tabular}{|c|c|c|}
\hline Project Potentiality & Project Actuality & Project Certainty \\
\hline Project Identification & Project Action Plan & Project Management Plan \\
\hline $\begin{array}{l}\text { - Establish strategic goals } \\
\text { - Identify procedure/contents } \\
\text { (elements/objectives) } \\
\rightarrow \text { Categorization } \\
\text { - Divide elements and items } \\
\text { - Make subdivided elements and } \\
\text { objectives numerically-specified } \\
\text { - PICS (Project Identifying \& } \\
\text { Categorizing Structure) }\end{array}$ & $\begin{array}{l}\text { - Actualize the implementation } \\
\text { of numerically-specified } \\
\text { objectives (means/methods) } \\
\text { - Work-breakdown of project } \\
\text { executors/executing organizations } \\
\text { - Identify CSF, KPI }\end{array}$ & $\begin{array}{l}\text { - Manage the performance } \\
\text { of project executors/executing } \\
\text { organizations based on the } \\
\text { Project Action Plan in terms of } \\
\text { time, cost, quality, safety, risk, } \\
\text { and change } \\
\text { - Manage the performance } \\
\text { and result of project executors/ } \\
\text { executing organizations }\end{array}$ \\
\hline
\end{tabular}

* Potentiality of dreams and visions achieves actuality through the establishment of project objectives and project action plan, and reaches certainty on the processes and outcomes of being-actualization through project management plan.

Figure 7 Development of project phenomenon from potentiality to actuality (Kim 2015) 
phenomenon of sustainability and relationality, aiming towards the successful episteme that reaches project success of an all-embracing perspective.

\section{Conclusion}

This paper identified from history that the vocation of mankind is being actualization, which is project actualization, and that successful episteme must precede the project's process and its outcome in order to achieve project success from an all-embracing perspective. By identifying and applying the intrinsic characteristics of the truthful episteme that drives toward the absolute knowing, I brought forward the conditions necessary for an all-embracing perspective of project success to overcome project executors' delusions caused by their emotional conviction. Through the conditions, I presented a new PICS in which the project goals and objectives are distinguished as temporal-spatial categories and gain concreteness as procedures and its contents under the properties of concepts, and comply with the sustainability of history and relationality of nature from the sameness of temporal-spatial categories. It also identified that confusion in episteme and complexity of project actualization process could be resolved by PLDC which is a logical development of two opposing thinking between project identification and action that appear in the consciousness activities of project phenomenon. The project identification, project action and management plan is the development of episteme to obtain a successful plan and outcome, leading towards an all-embracing perspective of project success. The Incheon Bridge Project, designed and completed by myself, was the first to be awarded the Premium Gold from Project Excellence Award in 2015 at the IPMA 50 ${ }^{\text {th }}$ World Congress, being recognized as a world-class benchmark, demonstrating a real case oriented towards an all-embracing perspective of project success. (Kim 2015).

Within the history of industrial development, human beings have driven changes through intervention in reality by the spirit and body, throughout the first industrial development by which machine substituted human labour, the second industrial development that facilitated mass production, computer-based third industrial development and the fourth industrial development represented by AI (Clark \& Cooke 2015). Thus diversity and complexity expanded across overall society in the areas of science, technology, politics, economy, society, culture, and so on. IoT and AI, as the core technologies of the fourth industrial revolution, are connecting humans to things, and reality to virtual reality. In this flow, the epistemic competence of project managers will expand to the orientation of successful episteme enabling success from an all-embracing perspective to be achieved. Project managers will possess future designing abilities that enable them to make design into reality, through the coexisting interrelationship of AI and spirit, as well as algorithms and logical concepts. This will provide a gateway of episteme that allows the integration of the various perspectives on the meaning of project success to be empathized. This paper is the journey of my episteme within the spirit that started from absolute knowing, self-realizing the correspondence of nature and sprit, to absolute knowledge, self-realizing that project plan corresponds with being actualization.

\section{References}

Abbasi, G. Y., \& Al-Mharmah, H. A. (2000). Project management practice by the public sector in a developing country. International Journal of Project Management 18, 105-109.

Clark W. W., \& Cooke, G. (2015). Industrial Development, In The Green Industrial Revolution, Butterworth-Heinemann, Boston, Pages 13-35. 
Cox Jr., F. (2016). The hidden success factor: look to the client - not scope, budget or timeline - to determine if the project succeeded or failed. PMNetwork, 30(2), 26-27.

Dvir, D., Raz, T., \& Shenhar, A. J. (2003). An empirical analysis of the relationship between project planning and project success. International Journal of Project Management, 21(2), 89-95.

Fichte, J. G. (1987). The Vocation of Man. (P. Preuss, Trans.). Indianapolis, IN: Hackett Publishing Company. (Original work published 1800).

Green, G. C. (2003). The impact of cognitive complexity on project leadership performance. Information and Software Technology, 46(3), 165-172.

Hegel, G. W. F. (1977). The Phenomenology of Sprit. (A. V. Miller, Trans.). Oxford, London: Oxford University Press. (Original work published 1807).

Heidegger, M. (1927/008). Being and Time. (J. Macquarrie \& E. Robinson Trans.). New York, NY: HarperCollins Publishers.

Hessen, J. (1964). Lehrbuch der Philosophie. Munchen, Germany: Ernst Reinhardt Verlag.

Ika, L. A. (2009). Project Success as a Topic in Project Management Journals: A Brief History. Project Management Journal, 40(4), 6-19.

International Project Management Association. (2016). IPMA Individual Competence Baseline.

Jugdev, K., \& Müller, R. (2005). A retrospective look at our evolving understanding of project success. Project Management Journal. 36(4), 19-31.

Kant, I. (1998). Critique of Pure Reason (P. Guyer \& A. Wood, Trans.). Cambridge, UK: Cambridge University Press. (Original work published 1781).

Kim, S. H. (2015). A philosophical approach to project management: Project as a phenomenon and the case of Incheon Bridge. Paper presented at the $29^{\text {th }}$ World Congress International Project Management Association (IPMA) 2015, Westin Playa Bonita, Panama.

Lacko, B., Polčáková, M., \& Bočková, H. (2014). Paradigm changes in Project Management and their impact on knowledge of project managers. Proceedings of the 2014 International Conference on Applied. Mathematics and Computational Methods in Engineering, Prague, Czech Republic.

Makridakis, S. (2017) The forthcoming Artificial Intelligence (AI) revolution: Its impact on society and firms, Futures, Volume 90, 46-60.

Mayo C. R., \& Leung, J. (2018). Artificial intelligence and deep learning - Radiology's next frontier, Clinical Imaging, 49, 87-88, https://doi.org/10.1016/j.clinimag.2017.11.007.

Meskendahl, S. (2010). The influence of business strategy on project portfolio management and its success -- A conceptual framework. International Journal of Project Management, 28(8), 807-817.

Milind, P., Gopinath, S. (2016). Six decades of project management research: Thematic trends and future opportunities. International Journal of Project Management, 34(7) 1305-1321.

Pinto, J. K. \& Slevin, D. P. (1988). Project success: definitions and measurement techniques. Project Management Journal, 19(1), 67-72.

Program Management Improvement Accountability Act (PMIAA) (2015).

Radujkovic, M., Sjekavica, M. (2017). Project Management Success Factors. Creative Construction Conference 2017, CCC 2017, 19-22 June 2017, Primosten, Croatia. 
Robertson, S. \& Williams, T. (2006). Understanding project failure: using cognitive mapping in an insurance project. Project Management Journal, 37(4), 55-71.

Schelling, F. W. (1979). System of Transcendental Idealism (P. Heath, Trans.). Charlottesville, VA: University Press of Virginia. (Original work published 1797).

Shaw, R. (2010). A research method for the future: Husserl's phenomenological method in management. Paper presented at ANZAM 2010, Wellington, New Zealand.

Shenhar, A. J., Levy, O., \& Dvir, D. (1997). Mapping the Dimensions of Project Success. Project Management Journal, 28(2), 5-13.

Stretton, A., \& Crawford, L. (2014). Bodies of Knowledge and Competency Standards in Project Management. The AMA Handbook of Project Management (pp. 13-28). New York; Atlanta; Brussels; Chicago; Mexico City; San Francisco; Shanghai; Tokyo; Toronto; Washington, D.C.: AMACOM Division of American Management Association International.

Stroud, B. (1986). The Physical World. Proceedings of the Aristotelian Society, 87, new series, 263-277. Retrieved from http://www.jstor.org.ezproxy.bu.edu/stable/4545066

Valverde S. Major transitions in information technology. Phil. Trans. R. Soc. B. 2016; 3711701:20150450. doi: 10.1098/rstb.2015.0450.

Whitehead, A. N., (1927/1979). Process and Reality. The Free Press.

\section{About the Author}

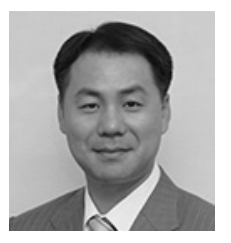

Honorary Doctor Soohong Kim is the CEO of Incheon Bridge Co., Ltd. and a chair professor at Kyungnam University. He also serves IPMA Korea as a vice chairman and a member of the National Academy Engineering of Korea.

Dr. Kim has been leading the Incheon Bridge, a national project of Korea throughout all the phases from business proposal to financing, construction, operation and management so far with a remarkable success, making new records in every step of the way. For the past 15 years since when the concept of project management was not yet established in Korea, Dr. Kim has dedicated himself to analysing Incheon Bridge project from a philosophical approach to view project as a phenomenon and applying his own methodologies to Incheon Bridge construction, operation and management. As a result, Incheon Bridge became the first successful case of national policy project to which project management had been fully applied.

Dr. Kim's business management philosophy which puts theory and practice together was captured in his paper 'A Philosophical Approach to Project Management: Project as a Phenomenon and the Case of Incheon Bridge' which was published by Elsevier on Procedia. His paper was recognized by the IPMA Scientific Committee for its original contribution and was introduced to the 29th IPMA World Congress and the 3rd IPMA Research Conference.

Dr. Kim has been awarded with a number of exceptional national and international prizes including the national highest Order of Industrial Service Merit-Gold Tower Medal awarded by the President of Republic of Korea, OCEA(Outstanding Civil Engineering Achievement) Award of Merit' by American Society of Civil Engineers(ASCE), IPMA Project Excellence Award Premium Gold Winner and Project Manager of the Year (silver) for his excellent project management achievements. 